\title{
Medical reporting recommendations: a gap between practical and theoretical approach of journalists in Italy
}

\author{
Marianna Di Croce ${ }^{(a)}$, Luisa Vercellesi ${ }^{(a)}$, Martina Laccisaglia ${ }^{(b)}$ and Flavia Bruno ${ }^{(a)}$ \\ ${ }^{(a)}$ Centro Studi Comunicazione sul Farmaco; ${ }^{(b)}$ Dipartimento di Scienze Farmacologiche, \\ Università degli Studi di Milano, Milan, Italy
}

\begin{abstract}
Objective. This survey involved medical reporters to identify degrees of theoretical and actual compliance to recommendations for health reporting. Methods. The questionnaire was addressed to 450 Italian journalists and obtained a redemption of 23.1\%. Results. Major gaps between theoretical agreement and professional practice were: need of scientific background and continuing education; importance of avoiding sensationalism, assessment of scientific protocols and results, reporting of results as absolute risk and numbers needed to treat, attention to the conflict of interest. Two homogeneous profiles emerged. Group 1 includes journalists working in newspapers and shows a large gap between theory and practice. Group 2 includes mainly journalists working in technical medical media and shows a higher consistency between the two settings. Discussion. An improvement in theoretical understanding of medical literature is advisable, but interventions are needed in the working practice in particular in newspapers, a setting where approaches are more difficult.
\end{abstract}

Key words: health communication, mass media, medical journalism, survey, quality.

Riassunto (Raccomandazioni per il giornalismo medico: discrepanza tra l'approccio pratico e quello teorico dei giornalisti in Italia). Obiettivi. Questa ricerca ha coinvolto giornalisti interessati a diffondere informazioni di carattere medico con lo scopo di identificare il loro livello di condivisione teorica e di applicazione pratica delle raccomandazioni per un buon giornalismo medico. Metodi. Il questionario ha raggiunto 450 giornalisti italiani e ottenuto una risposta del 23,1\%. Risultati. Le principali discrepanze fra l'atteggiamento teorico e l'applicazione professionale delle raccomandazioni riguardano l'utilità di una preparazione scientifica e di un aggiornamento continuo, l'attenta valutazione del protocollo e dei risultati sperimentali, l'esposizione dei risultati in termini di rischio assoluto e numeri necessari per il trattamento, l'attenzione ai conflitti di interesse. Dalle risposte sono emersi due profili omogenei. Il Gruppo 1 costituito dai giornalisti della stampa generalista che presenta un grosso divario fra teoria e pratica. Il Gruppo 2 che comprende quanti scrivono per i media specialistici e che dimostra una maggiore coerenza nei due ambiti. Discussione. Un miglioramento nelle capacità di interpretazione della letteratura biomedica è consigliabile, ma è anche necessaria, in particolare per quanto riguarda i quotidiani, un'attenzione alle modalità di lavoro nei quotidiani, un ambito nel quale gli interventi presentano maggiori difficoltà.

Parole chiave: comunicazione della salute, mass media, editoria scientifica, indagini, qualità.

\section{INTRODUCTION}

According to the Universal Declaration of Human Rights adopted by the United Nation Organization in 1948 as a common standard of achievement for all peoples and nations (Article 25), health and wellbeing are part of the universal rights belonging to every individual.

"Everyone has the right to a standard of living adequate for the health and well-being of himself and of his family, including food, clothing, housing and medical care and necessary social services, and the right to security in the event of unemployment, sickness, disability, widowhood, old age or other lack of livelihood in circumstances beyond his control".

Health is no longer considered as a lack of disease and well-being is a target for both personal and social equilibrium, to be protected through the adoption of correct lifestyles. Such an equilibrium should be achieved and maintained day after day both by single individuals and governmental, social and health boards. Nowadays in Western countries people live longer. Smallpox, polio, meningitis - the big killers of the past - seem to have disappeared; our health is endangered by our own approach to 
life: environmental pollution and incorrect lifestyles (cigarette smoking, lack of physical exercise, alcoholism, bad nutrition, drug abuse) are linked to the occurrence of tumors and cardiometabolic diseases, the first causes of death worldwide.

It is important to involve patients in the management of their health, to promote educational and social campaigns aiming to improve behaviours at risk. Considering both the difficulty in understanding the highly specialized scientific progress and the unclear journalistic reporting, it is essential to establish integrated health communication strategies for education and information $[1,2]$.

This scenario also requires quality journalism, in particular when dealing with health and medicine and internationally this is not always the case [3-6]. Scientific jargon, the difficult understanding of the level of evidence - all biomedical papers are interesting for the research, only a few may be relevant to the clinical practice - are just examples of barriers which medical reporters face when first selecting and then translating a fact into a news item. The information overload is a prominent aspect in the activity. Already a decade ago, the estimate of biomedical articles published in international journals was two million articles per year, but less than 5 per cent of them reported scientifically valid results which are useful in the medical practice [7]. Moreover the exponential growth of the web is offering new ways of communication and participation which enable everybody to become an author. A new communication form called "citizens' journalism" or "open source journalism" allows lay people to take part in the news-making process. In fact, we are witnessing a change in the news reporting: while traditional media are in crisis, information revolutionary tools are going to produce changes faster and faster both in consumption and in the production of information. Future journalism will be increasingly dependent on user contributions. The debate is still open. From one side the traditional media which want to keep information control and extensively use websites of press and communication agencies, international reviews and media channels in a very short time, from the other side new media which value citizens' effort in producing news, videoclips, images, photos, not always verifying the quality of information [8].

An international research of the London School of Economics reports that 8 out $10(81 \%)$ Italian web surfers search information on health, $65 \%$ on drugs, $47 \%$ tries a self diagnosis. Unfortunately three out of four do not pay attention to the reliability of sources, approaching in this way incorrect information. Women search the web for health topics more than men ( $83 \%$ vs $78 \%$ ); as expected young adults (25-34 years) both women and men are the key searchers for these topics. Moreover $13 \%$ of Italians participate in social media such as Facebook to post comments and queries and receive further elucidations on these topics [9].

Even more than in the past, a medical reporter is expected to keep a critical attitude towards the facts available from the many different sources (peer reviewed papers, media releases, grey literature, systematic revisions, congress presentations, press release) to decide whether the information has the prerequisites to become a news item to be addressed to the lay people. He has to decide how to translate it in a correct way to avoid false hope and hyperbole in order to balance the public impact. This critical attitude requires a scientific background to check the accuracy of the research protocol, the statistical methods and the results. A continuing education is necessary to prevent any form of sensationalism in terms and graphics and in particular to avoid forecast about the approval and the commercialisation of a new drug.

Reporting guidelines and practical recommendations for medical reporters are available internationally, focusing on selection, understanding and translating of health, medical and drug information. In a previous study, we have analysed the situation and detailed a thorough proposal, listing nearly 70 recommendations for medical and health reporting, endeavouring to answer the main criticisms of medical journalism, in respect of ethical, reliability, authoritative, updating, and independency issues. See Appendix for our recommendations which covers main phases for a good reporting, from education of the journalists, selection of the story to become a news report, assessment of sources, verification, contents of stories with particular attention to those related to drugs, follow up and nice to have aspects [10].

\section{OBJECTIVE}

In this research targeted to Italian medical reporters, we aimed to:

1. assess the degree of theoretical agreement and the actual compliance to recommendations in the working practice and highlight the difference between "theory" and "practice";

2. identify behavioural trends;

3. identify groups of medical reporters showing similar profiles.

\section{MATERIALS AND METHODS}

The survey was carried out in Italy and addressed to 450 journalists, all the members of UNAMSI (Unione NAzionale Medico Scientifica di Informazione), the professional association of medical and scientific journalists and other medical reporters of our acquaintance. The questionnaire included the most relevant items of our recommendations [10]. Questionnaires were sent by e-mail, accompanied by a telephone follow-up.

Descriptive statistics was applied to obtain a background assessment of the answers to the questionnaire and the difference between theoretical agreement and actual compliance.

Basket analysis was applied to identify trends in the theoretical and actual compliance.

Cluster analysis was applied to identify groups of medical reporters showing a similar degree of importance towards items which are conceptually correlated. 


\section{RESULTS}

The questionnaire was administered between April 20 and July 20, 2009. We obtained 104 responses (out of 450 contacts), corresponding to a redemption of $23.1 \%$.

Recommendations in theory and in practice: background assessment.

The results are summarized in Table 1, showing for the total of 104 respondents:

- percentages of theoretical agreement with each statement;

- the compliance in the working practice;

- the difference between "theory" and "practice" for each recommendation. The table has been ordered by this indicator.

For the comparison between theoretical approach and actual compliance, answers scoring at the top of the range have been used. Figure 1 graphically represents the same data.

\section{Behavioural trends (basket analysis)}

The following results derive from a deeper analysis of the answers obtained applying the basket analysis. Scientific background is considered important by almost $80 \%$ of respondents, as shown in Table 1 .

Table 1 | Theoretical agreement and actual compliance to recommendations (104 respondents)

\begin{tabular}{|c|c|c|c|c|}
\hline $\begin{array}{l}\text { Item } \\
\text { no. } \\
\text { (1) }\end{array}$ & Recommendation & $\begin{array}{c}\text { Theoretical } \\
\text { agreement with } \\
\text { recommendations } \\
\text { (high) }\end{array}$ & $\begin{array}{l}\text { Actual } \\
\text { compliance to } \\
\text { recommendations } \\
\text { (always) }\end{array}$ & $\begin{array}{l}\text { Difference } \\
\text { (2) }\end{array}$ \\
\hline 18. & Give to retractions the same space and emphasis of the rectified news item & 80.7 & 33.6 & 47.1 \\
\hline 10. & Consider research funding and any conflict of interest & 66.3 & 23.1 & 43.2 \\
\hline 11. & $\begin{array}{l}\text { Express statistical data in absolute terms (absolute risk) } \\
\text { and consider NNT (number needed to treat) }\end{array}$ & 62.5 & 21.1 & 41.4 \\
\hline 4. & Remember that peer reviewed papers offer more guarantee & 70.2 & 30.8 & 39.4 \\
\hline 14. & $\begin{array}{l}\text { Provide complete information on drugs (not only indications, but also } \\
\text { contraindication frequency and severity of adverse effects); } \\
\text { consider a drug as innovative only if it defines a new class II or III in ATC }\end{array}$ & 80.8 & 45.2 & 35.6 \\
\hline 7. & Assess accuracy of the research protocol & 69.2 & 34.6 & 34.6 \\
\hline 5. & $\begin{array}{l}\text { Consider possible conflict of interest of the source particularly with } \\
\text { reference to disease mongering }\end{array}$ & 78.8 & 45.2 & 33.7 \\
\hline 9. & Assess clinical relevance and use of study results & 77.9 & 44.2 & 33.7 \\
\hline 8. & Verify that results are final & 68.3 & 36.5 & 31.8 \\
\hline 17. & $\begin{array}{l}\text { Do not restrict information to "sensationalism facts"; } \\
\text { follow up its evolution in time }\end{array}$ & 80.7 & 48.1 & 32.6 \\
\hline 6. & $\begin{array}{l}\text { Consider relevance of the study (e.g. case reports, analytical or descriptive } \\
\text { studies, in vitro or animal studies, clinical studies) }\end{array}$ & 84.6 & 52.9 & 31.7 \\
\hline 2. & $\begin{array}{l}\text { Assess reliability and authoritativeness of sources even of institutional } \\
\text { ones (universities, agencies) }\end{array}$ & 82.6 & 49.2 & 33.4 \\
\hline 3. & $\begin{array}{l}\text { Consider relation between source (peer reviewed papers, media releases, } \\
\text { grey literature, systematic revisions, congress presentations) }\end{array}$ & 75.9 & 45.2 & 30.7 \\
\hline 1. & Need of a scientific background and continuing education & 77.9 & 48.1 & 29.8 \\
\hline 12. & Avoid any form of sensationalism in terms and graphics & 85.6 & 62.5 & 23,1 \\
\hline 15. & Be cautious with off-label indications of drugs & 84.7 & 64.4 & 20.3 \\
\hline 13. & Avoid forecast about approval and commercialisation of a new drug & 77.9 & 59.6 & 18.3 \\
\hline 16. & $\begin{array}{l}\text { Keep into account the emotional impact of news items on lay } \\
\text { and diseased public }\end{array}$ & 93.3 & 77.9 & 15.4 \\
\hline
\end{tabular}

(1) Numbers in the first column refer to the order of questions as addressed in the survey.

(2) Items are listed in this table according to the highest difference between theory and practice greatest gap between theoretical agreement and practical compliance. 

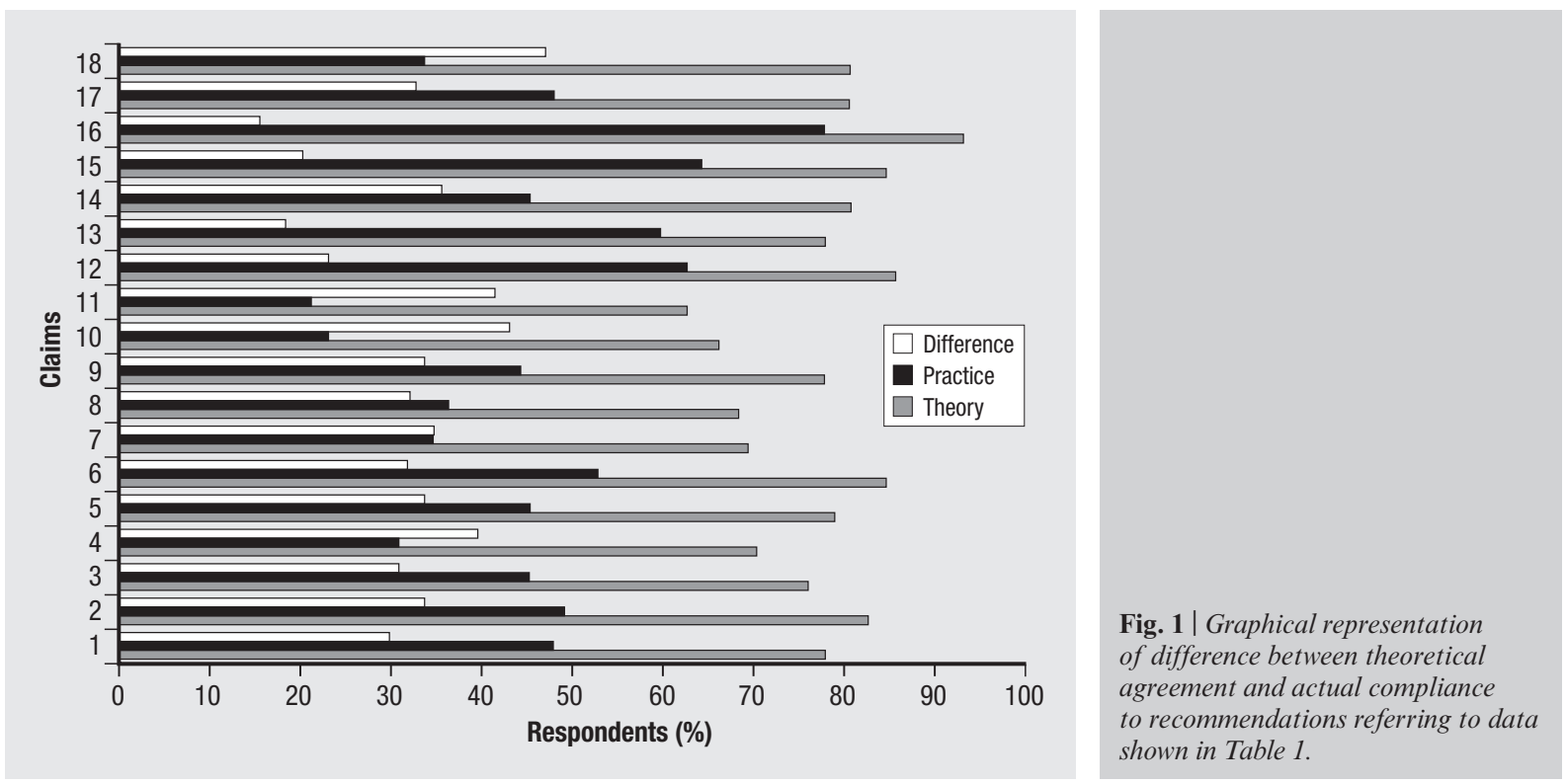

The answer to this item should be consistent with the two answers to items regarding the comprehension of the clinical study and its statistical methods. However there are inconsistencies; in the working practice, those respondents who claim to evaluate the accuracy of the statistical methods, do not consider scientific background as much as important neither in theory nor in actual practice; similarly, when scientific background is considered very important, the interpretation of methods and statistical parameters appear not to gain a similar attention.

In other words, $80 \%$ of the respondents considers very important a scientific background, but a lower attention is given to the comprehension of the clinical study and the statistical parameters, which are prerequisites of the scientific education.

Two items in the questionnaire referred to the conflict of interest to ascertain the conflict of interest indicated in the scientific publication and to report funding and conflict of interest in the news item. The importance attributed to individual answers is high, but their association is practically nil.

Sources are dealt with in three items: "assess the reliability of sources", "consider the relation source-scientific evidence" and "importance of peer reviewed papers". The first two items are considered important both in theory and in the actual setting. Less agreement is shown for the third item. The association among the three items shows an inconsistency.

The answers on emotional impact show a good consistency for all items, such as attention to emotional impact, use of terms, providing complete information on drugs.

Follow up: this concept is dealt with in two items: "follow-up to the news" and "retraction"; there is no inconsistency between the two, even if their practice is low.

\section{Groups of medical reporters showing similar profiles (cluster analysis)}

The cluster analysis tries to identify a small number of groups with high homogeneity: the groups were identified according to their low or high difference between "theory" and "practice" and including the variable "type of professional activity". In our case, we identified two main groups (see Table 2):

Group 1 (No. $=32,32.5 \%)$ shows a high difference between "theory" and "practice" regarding scientific background and relevant items (relevance of the study, relationship between sources and level of scientific evidence, importance of sources). In addition, also the item "attention to follow up," shows a high difference, a trend which is not apparent in other groups. This group includes a number of professionals working in newspapers and thus primarily targets lay people.

Group $2($ No. $=28 ; 26.9 \%)$ shows a clear consistency between "theory" and "practice" for all the items in the questionnaire. This group includes medical reporters involved in technical medical journals targeted to health professionals.

\section{DISCUSSION AND CONCLUSION}

Our study is providing a step forward in understanding the process of medical reporting leading to "miscommunication", a situation which has been recognized for years [11].

We have in fact involved reporters on a series of recommendations asking them to express their views about their theoretical agreement and the actual compliance to the items.

The redemption to our survey exceeding 20\% has been remarkable, considering the direct contact through e-mail, showing the sensitivity in the topic addressed. Respondents are not a statistical sample 


\begin{tabular}{|c|c|c|c|c|}
\hline & \multicolumn{2}{|c|}{$\begin{array}{c}\text { Group } 1 \\
\text { (32 respondents) }\end{array}$} & \multicolumn{2}{|c|}{$\begin{array}{c}\text { Group } 2 \\
\text { (28 respondents) }\end{array}$} \\
\hline & No. of respondents & Percentage & No. of respondents & Percentage \\
\hline Newspapers & 4 & 12.5 & 0 & 0 \\
\hline Lay magazines & 9 & 28.1 & 8 & 28.6 \\
\hline Technical medical media & 2 & 6.2 & 5 & 17.8 \\
\hline Public Agencies & 8 & 25 & 4 & 14.3 \\
\hline Web & 3 & 9.5 & 3 & 10.7 \\
\hline Freelance & 6 & 18.7 & 8 & 28.6 \\
\hline
\end{tabular}

of the Italian medical journalists or lay journalists reporting on health and medical issues, for whom no professional association exists. However, in our opinion the number of answers attributes a particular importance to the results considering that we have involved in our survey all the members of the Italian Association of Medical Scientific Journalism (UNAMSI, Unione NAzionale Medico Scientifica di Informazione) and all the journalists who we know are involved in medical reporting.

The questionnaire used in the survey has been condensed from all the available recommendations, totalling to 70 [10]. It focuses on those issues bringing the medical reporter in front of the scientific method: primarily source, assessment of the protocol, level of scientific evidence, how to express risk and to select news items papers showing clinical outcomes. The decision to summarize 70 items has been taken to shorten the questionnaire to one page and thus enhance the redemption.

The analysis of the theoretical answers outlines a basic literacy in medical reporting; however some typical aspects of medical research are overlooked: funding and conflict of interest, understanding of the need to report results in absolute terms and consider NNT (number needed to treat), accuracy of methodology and attention to the preliminary nature of results. Reasonably this makes it difficult to assess facts effectively in the light of the advocated evidence-based journalism.

Our results are not dissimilar from those obtained in a previous European survey conducted among 110 Swedish medical reporters, with a response rate of $55 \%$ [12] In this case, fact-giving, stimulating, and critical functions were rated as the most important journalist role attributes, followed by advocacy of patient interests and of public health goals. Major perceived problems were self-imposed professional demands, job stress, knowledge and time constraints, selection and contextualization of news material. Respondents' opinions on the appropriateness of specific ethical rules or guidelines for medical journalists were clearly divided.

For all the items investigated, the actual compliance to recommendations is lower than the matching theoretical agreement. In this study we did not foresee to enquire about the reasons justifying this difference, even if this is something which could be interesting to investigate.

The low attention to conflict of interest in actual practice which emerged in our survey is in line with other studies $[13,14]$. This is a strong limitation to the understanding of the reliability and authoritativeness of the information; the lack of reporting of funding and sponsorship deprives the reader of an aspect which helps to put the news items in a thorough perspective. In case of news items on drugs and disease mongering, the lack of this information acquires a particular importance.

Clearly respondents claim to pay great attention to sources, a prerequisite of the journalistic practice in every field; however the attention given to peer reviewed papers is scarce (around $30 \%$ ); which may be explained with the need to satisfy one of the typical aspect of the journalism, novelty - which can be found more frequently in congress presentations, a way of diffusion not following the peer review process.

It is worth noting that reporters classified as Group 1 shows a marked difference between "theory" and "practice"; this group includes a number of journalists working primarily in newspapers (no newspaper journalist is included in Group 2, the group showing a high consistency between "theory" and "practice"); it has been long known that newspapers are the communication channel through which decision makers may be originally informed of the medical progress [15] and this means that they are not receiving the best of information.

In the recent past, two approaches have been advocated to enable journalists to improve medical reporting:

- the new precision journalism. The school of new "precision journalism" holds that mass communication journalists should employ the same methods as scientists, i.e. scientific method, scientific objectivity, and scientific ideals [16], with particular regard to medicine and health; 
- the evidence based journalism [17] which, recalling the concept of evidence based medicine, stresses the need that media outlets have as much responsibility as ever to maintain standards.

Public, professionals, decision makers deserve sound reporting of discoveries, however funded, and possible benefits to health. No researcher can (or should) control how their words will be interpreted or discussed, but all parties involved in debates about scientific and medical discoveries must remember a responsibility imposed by the public interest [18]. Most of the news items origin from media releases; thus it is essential that researchers spend appropriate time to revise and approve this form of communication as they do with scientific publications [19].

An aspect which our survey did not investigate is the selection of topics: a trend exists to report on key emerging diseases, such as the influenza pandemic, decreasing the relative level of attention and the risk perception to the big killers, cancer and cardiometabolic diseases. This is what derives from a recent Korean study [20], which confirms the situation seen by us in Italy (unpublished data).

However our results appear to show that at least in Italy an improvement in theoretical understanding is advisable, but it is in the working practice that interventions are needed and this is a field where

\section{References}

1. Jucks R, Paus E, Bromme R. Patients'medical knowledge and health counseling: What kind of information helps to make communication patient-centered? Patient Educ Couns 2012. Feb 22.

1http://dx.doi.org/10.1016/j.pec.2012.01.011

2. Centers for Disease Control and Prevention. Health Communication Strategies. Available from: www.cdcnpin.org/scripts/ campaign/strategy.asp. Accessed March 23, 2012.

3. Larsson A, Oxman AD, Carling C, Herring J. Medical messages in the media. Barriers and solutions to improving medical journalism. Health Expect 2003;6:323-31. http://dx.doi.org/10.1046/j.1369-7625.2003.00228.x

4. Lai YY, Lane T. Characteristics of medical research news reported on front page of newspapers. PLos One 2009;4(6): e6103.

http://dx.doi.org/10.1371/journal.pone.0006103

5. Schwitzer G. How do US journalists cover treatments, tests, products, and procedures? An evaluation of 500 stories. PLos Med 2008;5(5):e95.

http://dx.doi.org/10.1371/journal.pmed.0050095

6. Hochmann M, Hochmann S, Bor D, McCornick D. News media coverage of medical research. JAMA 2008;300(13):1544:50. http://dx.doi.org/10.1001/jama.300.13.1544

7. Barbour V, Clark J, Peiperl L, Veitch E, Wong M, Yamey G. False hopes, unwarranted fears: the trouble with medical news stories. PLoS Med 2008;5(5):e118. http://dx.doi.org/10.1371/journal.pmed.0050118

8. Pratellesi M. New journalism. Milano: Mondadori; 2008.

9. Bupa Health Pulse 2010. Available from: www.bupa.com/ about-us/information-centre/bupa-health-pulse/bupahealth-pulse-2010 (accessed March 23, 2012).

10. Vercellesi L, Minghetti P, Di Croce M, Bazzi B, et al. Rec- approaches are more difficult. These results do not appear to support a recent paper [21] in which authors examined whether experienced specialist health reporters write better stories than other categories of journalists and concluded that "it does matter who writes news stories that cover the benefits and harms of health care interventions. Stories written by specialist health journalists working for a single media outlet scored more highly than those written by less experienced writers". Instead, in our survey we have seen that the reporters writing for technical medical media targeted to health professionals are more consistent between their theoretical views and actual practice.

\section{Acknowledgments}

The authors thank Stefano Maria Iacus, University of Studies of Milan, for his support in statistical analysis.

\section{Conflict of interest statement}

There are no potential conflicts of interest or any financial or personal relationships with other people or organizations that could inappropriately bias conduct and findings of this study.

Received on 25 January 2012.

Accepted on 26 April 2012. ommendations for health reporting: Proposal of a working paper. Health Educ J 2010;69(1)48-6. http://dx.doi.org/10.1177/0017896909349300

11. Shuchman M, Wilkies MS. Medical scientists and health news reporting: a case of miscommunication. Ann Intern Med 1997;26:976-82.

12. Finer D, Tomson G, Bjorkman NM. Ally, advocate, analyst, agenda-setter? Positions and perceptions of Swedish medical journalists. Patient Educ Couns 1997;30(1):71-81. http://dx.doi.org/10.1016/S0738-3991(96)00960-3

13. Cook DM, Boyd EA, Grossmann C, Bero LA. Reporting science and conflicts of interest in the lay press. PLoS One 2007;2(12):e1266. doi:10.1371/journal.pone.0001266. http://dx.doi.org/10.1371/journal.pone.0001266

14. Hochman M, Hochman S, Bor D, McCormick. Generic medication names of reporting pharmaceutical company funding and use news. JAMA 2008;300(13):1544-50. http://dx.doi.org/10.1001/jama.300.13.1544

15. Cook FM, Tyler TR, Goetz EG, Gordon MT, Protess D. Media and agenda setting: effects on the public, interest group leaders, policy makers, and policy. J Federalism 1983;47(1):16-35 http://dx.doi.org/10.1086/268764

16. Meyer P. The new precision journalism. Boston, USA: Rowman \& Littlefield Publishers, Inc; 2001.

17. Swan N. Evidence based journalism Med J Aust 2005;183(4): 194-5.

18. Editorial. The truth about science. The Lancet 2010;376(9746): 1026. http://dx.doi.org/10.1016/S0140-6736(10)61468-7

19. Jones S. Bad seeds, bad science, and fairly black cats? Lancet 2010;376(9750):1384-5. http://dx.doi.org/10.1016/S0140-6736(10)61944-7 
20. You M, Ju Y. News media's surveillance and gatekeeping in representing health risks. J Prev Med Public Health 2010;43(3):279-82.

http://dx.doi.org/10.3961/jpmph.2010.43.3.279

\section{Appendix:}

1. Education. We recommend a specific background and continuing education.

2. Selection. We advise journalists to:

- consider medical papers alerted from scientific journals for media diffusion;

- read abstracts for patients, when available;

- consider papers published in peer-reviewed journals, with their innate exceptions and limits, as a major guarantee;

- select from papers commented on in editorials;

- be careful with results presented at congresses, which do not undergo the peer-review process;

- be cautious with press releases and handouts from press briefings and refer to the original publication;

- be cautious of unpublished work;

- assess works presented in media releases or conferences by the academic institute that did the research;

- avoid wasting time with inaccurate or inconclusive research and be careful with preliminary results;

- do not use studies based solely on statistical extrapolations and findings;

- assess the sample and its statistical value; avoid studies with small and unrepresentative samples;

- assess the accuracy of the statistical method and type of study;

- consider alternative explanations or interpretations for the results;

- find out what stage the clinical trial is at;

- identify those results that indicate an association rather than a casual link;

- watch out for disease mongering;

- read the papers in the light of the news values;

- avoid reporting of anecdotal cases, unusual evidence, individual voices, even if they all have great journalistic value;

- assess whether international data can be extrapolated to the local situation;

- assess the potential impact on your audience.

3. Assessment of sources. We recommend that journalists should: - consider the reliability, authoritativeness and current interest of the sources;

- consider the reputation of the academic institutions that did the research, even if particular affiliations are at times disputable;

- consider the reputation of the research group and of the authors and their publication track record;

- watch out for clear or hidden conflicts of interest of any nature (between researchers and industry, personal interest of researchers and socio-economical);

- be very careful when using abstracts, news releases, wire reports, or other secondary sources of information;

- be careful also with peer reviewed articles;

- consider the "positive result" publication bias;

- use the same parameters for all sources.

4. Verification. Under this item, we recommend to:

- be rigorous in your investigation;

- cross check the information with other sources;

- consider if results differ markedly from previous studies and contradict mainstream scientific opinions;

- ask for a second opinion from other members of the scientific community, particularly in the case of controversial issues;

- analyze critically the data, especially if distributed by industry, at press conferences or in press releases;

- check whether the results differ significantly from those reported in earlier studies and try to find a reasonable explanation;

- consider what we already know and what is new.
21. Wilson A, Robertson J, McElduff P, Jones A, Henry D. Does it matter who writes medical news stories? PLoS Med 2010;7(9).

http://dx.doi.org/10.1371/journal.pmed.1000323

\section{Contents of stories:}

- base the story on reading the full paper;

- always indicate your sources;

- make a distinction between data (facts) and opinions (theory);

- draw a clear line between science facts and faith hopes;

- indicate the strength and power of the results presented;

- make a quantitative estimate of the benefits using absolute data and NNT (numbers needed to treat to obtain the benefit);

- specify whether tests were in vitro or in animals, and indicate the potential clinical relevance;

- state clearly if the results are not final and when firm proof might be available;

- state why no assurance can be given about results, or if there is no absolute certainty;

- outline the natural course of the disease;

- indicate funding;

- avoid sensationalism in the title, captions, images, tables and info-graphics;

- avoid the dissemination of public health alarms and false hopes;

- indicate the value of a risk factor, by comparing it, for instance, with the weight of other risks;

- use words like: "may", "could", "claims", "possible", "potential";

- avoid words like: "cure", "miracle", "breakthrough", "promising", "dramatic", "hope", "victim", "zero risk", "medical miracle";

- reduce coverage of suicide stories to avoid copycats;

- consider the principle of precaution.

\section{Contents for drug stories:}

- call a drug "innovative" only if from it derives a new II or III class in the ATC classification;

- call a drug "new" only if it has been available for less than two years;

- be cautious with off-label drugs or indications;

- avoid efficacy statements for phase I and II studies, which are meant to evaluate safety; "or run in small numbers of patients";

- indicate whether the drug is locally available on prescription and reimbursed by National Health System;

- indicate the clinical effects of the drug;

- always provide information on warnings, contraindications, frequency and severity of adverse reactions;

- avoid encouraging drug consumption;

- avoid encouraging the use of drugs in situations that are not pathological or are still controversial;

- set the drug in its appropriate context by comparing it with existing drug and non drug options, including careful watching;

- report the cost compared to existing therapies, and state whether generic drugs are available for the same indication;

- stress the doctor's role in relation to prescription drugs;

- avoid mentioning regulatory approval, which is not automatic.

\section{Follow-up is critical:}

- make any corrections as obviously and promptly as the original article;

- provide similar emphasis to retractions as to original article;

- follow-up on the topic from the international literature.

8. Page lay-out and "nice to have":

- avoid mixing information and advertising;

- indicate an expert to contact for advice;

- identify local centres of excellence;

- create a clear framework;

- ask the editor for space for discussion and comparison;

- use of infographics. 